\title{
Les confréries dans le gouvernement de Québec sous le Régime français
}

\section{Marie-Aimée Cliche}

Volume 39, numéro 4, printemps 1986

URI : https://id.erudit.org/iderudit/304399ar

DOI : https://doi.org/10.7202/304399ar

Aller au sommaire du numéro

Éditeur(s)

Institut d'histoire de l'Amérique française

ISSN

0035-2357 (imprimé)

1492-1383 (numérique)

Découvrir la revue

Citer cet article

Cliche, M.-A. (1986). Les confréries dans le gouvernement de Québec sous le Régime français. Revue d'histoire de l'Amérique française, 39(4), 491-522. https://doi.org/10.7202/304399ar d'utilisation que vous pouvez consulter en ligne.

https://apropos.erudit.org/fr/usagers/politique-dutilisation/ 


\title{
LES CONFRÉRIES DANS LE GOUVERNEMENT DE QUÉBEC SOUS LE RÉGIME FRANÇAIS
}

\author{
MARIE-AIMÉE CLICHE \\ Département d' histoire \\ Université Laval
}

Pendant la période de la Contre-Réforme, l'épiscopat français se livra à un effort soutenu pour améliorer l'instruction religieuse du peuple, l'inciter à une fréquentation régulière des sacrements, lui inculquer une dévotion centrée sur Dieu et le Christ, et resserrer l'encadrement paroissial autour des fidèles. Simultanément, il entreprit de modifier certaines coutumes qu'il jugeait incompatibles avec le respect dû à Dieu comme la très grande familiarité dans les lieux saints et les festivités profanes lors des fêtes religieuses ${ }^{1}$.

Les confréries constituaient un moyen pour atteindre ces objectifs. Les évêques en créèrent plusieurs destinées à développer la foi aux grands mystères de la religion: par exemple, au Christ dans l'Eucharistie, à la mère de Dieu. Ces associations assignaient à leurs membres des obligations spirituelles (réception des sacrements, participation aux offices et processions, prières privées, entretien d'une chapelle), morales (éviter les cabarets, le jeu, la danse) et sociales (secourir les pauvres et les malades, prier pour les confrères défunts) ${ }^{2}$.

A côté de ces nouvelles confréries subsistaient les anciennes: celles des pénitents et des différents métiers. Le clergé post-tridentin ne les regardait pas d'un oeil favorable à cause de leur habitude de célébrer leur fête patronale par un banquet qui tournait facilement à la ripaille. En outre, leurs réunions empiétaient parfois sur l'office paroissial et échappaient au contrôle du curé ${ }^{3}$. Les évêques supprimèrent un certain nombre de ces associations qu'ils jugeaient coupables de déviations ou d'abus ${ }^{4}$. Mais surtout, ils réussirent à imposer aux nouvelles confréries la demande d'autorisation préalable qui permettait de préciser leurs buts et d'établir un contrôle permanent ${ }^{5}$.

\footnotetext{
1 Sur ce sujet, consultez entre autres, La Religion populaire (Paris, CNRS, 1979), 449 p. (Actes du colloque international du CNRS, 1977).

2 Louis Pérouas, «Entre le XVIe et le XIXe siècles, des regards différents sur le culte des saints en Limousin», dans La Religion populaire, 90.

${ }_{3}$ Arlette Playoust-Chassis, La vie religieuse dans le diocèse de Boulogne au XVIIIe siècle (Arras, 1976), 257-258. 165.

Abel Poitrineau, dir., Histoire du diocèse de Clermont (Paris, Beauchesne, 1979), $164-$

Gabriel Le Bras, L'église et le village (Paris, Flammarion, 1976), 163.
} 
Le clergé et les premiers immigrants français transplantèrent rapidement au Canada quelques-unes des confréries qu'ils avaient connues dans leur pays d'origine. Ils en fondèrent huit dans le gouvernement de Québec sous le Régime français. Ce sont, par ordre chronologique: les confréries du Rosaire et du Scapulaire, en 1656, celle de Sainte-Anne et la congrégation de la Vierge, en 1657, la Sainte-Famille, en 1664, le tiers ordre franciscain et la congrégation des filles externes à une date inconnue durant le 17e siècle, et la confrérie du Sacré-Coeur en 1716. Implantées à Québec, la plupart de ces associations se répandirent ensuite dans les paroisses rurales.

Les ecclésiastiques de la colonie visaient-ils les mêmes objectifs que leurs confrères de France en fondant ces associations pieuses? Il est possible de le savoir en parcourant les lettres d'établissement, les statuts et les règlements des confréries, toujours rédigés par un évêque ou un prêtre.

Pour connaître la réaction de la population à cet aspect de l'enseignement de l'Église, il faut d'abord mesurer l'ampleur du recrutement des confréries, puis étudier leurs activités. Les registres des membres, les livres de comptes et les procès-verbaux des assemblées, plus quelques sources parallèles, nous renseignent sur ce sujet.

Malgré d'inévitables lacunes, cette documentation permet de saisir l'apport des confréries dans la vie religieuse de la colonie et de faire ressortir, par comparaison avec la France, les traits distinctifs de ces organisations dans la région de Québec ${ }^{6}$.

\section{I - L'OBJECTIF : ANIMER LA DÉVOTION POPULAIRE}

Même si une confrérie voyait le jour grâce à une initiative d'un laïc, comme ce fut le cas pour celles du Rosaire, de Sainte-Anne et de la Sainte-Famille, la hiérarchie ecclésiastique intervenait toujours pour en confier la direction à un prêtre, accorder une autorisation officielle, octroyer des indulgences, ainsi que pour préciser les objectifs communs et particuliers de chaque association.

La similitude des termes employés dans les lettres patentes, les bulles papales et les oraisons d'entrée suffit à elle seule à faire ressortir les traits communs des confréries. Soucieux d'assurer le salut des âmes confiées à leurs soins, les pasteurs invitaient leurs ouailles à pratiquer une dévotion particulièrement importante en s'associant à une confrérie pour honorer le saint patron, se placer sous sa protection et participer aux prières collectives.

6 Le présent travail est tiré de notre thèse de doctorat en histoire intitulée: «La religion populaire dans le gouvernement de Québec sous le Régime français d'après la pratique des actes surérogatoires», Université Laval, 1984. Le lecteur pourra y trouver des informations détaillées que cet article ne peut contenir pour des raisons d'espace. 
La façon la plus recommandée d'honorer le saint patron consistait à imiter ses vertus. Comme l'oeuvre de sanctification chrétienne ne peut s'accomplir qu'en union avec le Christ, les règlements prescrivaient la fréquentation assidue des sacrements de pénitence et d'eucharistie. A cela s'ajoutaient des actes de culte extérieurs comme des messes solennelles et des processions lors des fêtes principales et secondaires de l'association, et la décoration de la chapelle. Les membres d'une confrérie considéraient également leur patron comme un protecteur spécial et lui demandaient son aide dans toutes les actions de leur vie et à l'heure de la mort. Enfin, ces groupements pratiquaient l'entraide spirituelle car les règlements prescrivaient de prier pour les confrères défunts et parfois de secourir les malades et les pauvres.

En échange de la participation aux prières collectives et de certaines oeuvres pies accomplies en privé, les associés pouvaient gagner des indulgences partielles ou plénières (tableau 1). Mais, dans ce dernier cas, il fallait d'abord se convertir, c'est-à-dire être véritablement pénitents, se confesser et communier. L'énoncé de ces conditions montre bien que le clergé recherchait l'amélioration de la vie morale et spirituelle des gens et que l'octroi des indulgences ne devait pas se ramener à un simple marchandage ${ }^{7}$.

Pour atteindre l'objectif qui était d'animer la dévotion des fidèles, chaque confrérie suivait une voie distincte. Chacune des associations avait un patron attitré ${ }^{8}$, certaines prônaient la pratique d'une vertu en particulier, d'autres avaient un mode de recrutement spécial.

Deux stratégies se dégagent assez nettement dans la façon de recruter les membres des confréries et de leur fixer des objectifs spéci-

7 Le tableau 1 a été dressé à partir des sources suivantes: Bulle des indulgences accordées à la Sainte-Famille pour les âmes du purgatoire, 1665, dans Henri Têtu et C.-O. Gagnon, Mandements et Lettres pastorales des évêques de Québec (Québec, Côté, 1887), I: 53-54 (dorénavant MEQ). Bulle d'Alexandre VI contenant les indulgences accordées à la confrérie de la SainteFamille de Québec, 1665, Ibid., I: 54-56. APNDQ, Ms 34. «Indulgences accordées aux confrères de Sainte-Anne par la bulle du pape Innocent XI en date du 15 mars 1694», dans le Petit livre des pratiques de dévotion des confréries de Sainte-Anne, du Rosaire et du Scapulaire. Bulle du pape Innocent $\mathrm{X}$ contenant les indulgences accordées à la confrérie du Rosaire de Notre-Dame de Québec, 5 février 1654, reproduite dans Instructions sur les dévotions du Saint-Rosaire et du Saint-Scapulaire (Québec, C. Lefrançois, 1821), 90-95. Abrégé des indulgences de la confrérie du Scapulaire, dans Ibid., 118-123. Bulle du pape Clément XI contenant les indulgences accordées à la confrérie du Sacré-Coeur établie au monastère des Ursulines de Québec, 8 mars 1718, dans Lionel Lindsay, Les origines de la dévotion au Sacré-Coeur de Jésus au Canada (Montréal, A. P. Pigeon, 1900), 71 p. AAQ, Bulle du pape Innocent XII accordant à la chapelle de Sainte-Anne dans la cathédrale de Québec le privilège de l'autel privilégié, 1694. Bulle de Benoît XIII, dans Faillon, Histoire de la Congrégation Notre-Dame, II: 223-224. Bulle du pape Grégoire XIII accordant des indulgences aux Congrégations, 5 décembre 1584, dans Joseph Trudelle, Églises et chapelles de Québec (Québec, 1902), I: 398-400. Reuben Gold Thwaites, éd., Relations des Jésuites (Cleveland, Burrows Bros., 1896-1901), 66: 210. (Dorénavant $R J$ ). Lettre du père Germain, 1711.

8 La confrérie du Sacré-Coeur constitue un cas un peu différent car elle prônait une dévotion réparatrice. L'oraison d'entrée et les règlements de quatre confréries au moins mentionnent l'obligation d'imiter les vertus du patron. 
TABLEAU 1

Répartition des indulgences entre les confréries

\begin{tabular}{|c|c|c|c|c|c|c|c|}
\hline & $\begin{array}{l}\text { Congrégation } \\
\text { des filles }\end{array}$ & $\begin{array}{l}\text { Congrégation } \\
\text { de la Vierge }\end{array}$ & $\begin{array}{l}\text { Sainte- } \\
\text { Famille }\end{array}$ & $\begin{array}{l}\text { Sainte- } \\
\text { Anne }\end{array}$ & Rosaire & Scapulaire & $\begin{array}{l}\text { Sacré- } \\
\text { Coeur }\end{array}$ \\
\hline $\begin{array}{l}\text { Se confesser et communier le jour de } \\
\text { l'admission }\end{array}$ & Plénière & Plénière & Plénière & Plénière & Plénière & Plénière & Plénière \\
\hline $\begin{array}{l}\text { Se confesser et communier ou prier à } \\
\text { l'article de la mort }\end{array}$ & Plénière & Plénière & Plénière & Plénière & Plénière & Plénière & Plénière \\
\hline $\begin{array}{l}\text { Se confesser et communier à la fête } \\
\text { patronale }\end{array}$ & Plénière & Plénière & Plénière & Plénière & Plénière & Plénière & Plénière \\
\hline $\begin{array}{l}\text { Aller prier à la chapelle de la confré- } \\
\text { rie le jour des } 4 \text { fêtes secondaires }\end{array}$ & $\begin{array}{l}7 \text { ans et } \\
7 \text { quarantaines }\end{array}$ & Plénière & $\begin{array}{l}7 \text { ans et } \\
7 \text { quarantaines }\end{array}$ & $\begin{array}{l}7 \text { ans et } \\
7 \text { quarantaines }\end{array}$ & $\begin{array}{l}7 \text { ans et } \\
7 \text { quarantaines }\end{array}$ & $\begin{array}{l}7 \text { ans et } \\
7 \text { quarantaines }\end{array}$ & $\begin{array}{l}7 \text { ans et } \\
7 \text { quarantaines }\end{array}$ \\
\hline $\begin{array}{l}\text { Assister aux messes, offices et } \\
\text { assemblées de la confrérie }\end{array}$ & 60 jours & 1 an & 60 jours & 60 jours & 60 jours & 100 jours & \\
\hline $\begin{array}{l}\text { Faire un examen de conscience quo- } \\
\text { tidien }\end{array}$ & & 1 an & & & & & \\
\hline $\begin{array}{l}\text { Entendre la messe les jours } \\
\text { ouvrables }\end{array}$ & & 1 an & & & & & \\
\hline Réconcilier des ennemis & 60 jours & & 60 jours & 60 jours & 60 jours & 100 jours & \\
\hline Loger les pauvres & 60 jours & & 60 jours & 60 jours & 60 jours & 100 jours & \\
\hline Accompagner un convoi funéraire & 60 jours & 1 an & 60 jours & 60 jours & 60 jours & 100 jours & \\
\hline Assister à une procession & 60 jours & & 60 jours & 60 jours & 60 jours & & \\
\hline $\begin{array}{l}\text { Accompagner le Très-Saint- } \\
\text { Sacrement }\end{array}$ & 60 jours & & 60 jours & 60 jours & 60 jours & $\begin{array}{l}5 \text { ans et } \\
5 \text { quarantaines }\end{array}$ & \\
\hline $\begin{array}{l}\text { Réciter } 5 \text { Pater et } 5 \text { Ave pour con- } \\
\text { frères défunts }\end{array}$ & 60 jours & & 60 jours & 60 jours & 60 jours & & \\
\hline $\begin{array}{l}\text { Ramener quelqu'un dans le chemin } \\
\text { du salut }\end{array}$ & 60 jours & & 60 jours & 60 jours & 60 jours & & \\
\hline $\begin{array}{l}\text { Enseigner aux ignorants les vérités } \\
\text { de la foi }\end{array}$ & 60 jours & & 60 jours & 60 jours & 60 jours & & \\
\hline $\begin{array}{l}\text { Accomplir une oeuvre de piété ou de } \\
\text { charité }\end{array}$ & 60 jours & & 60 jours & 60 jours & 60 jours & 100 jours & \\
\hline $\begin{array}{l}\text { Réciter } 3 \text { fois une oraison à sainte } \\
\text { Anne devant une image de sainte } \\
\text { Anne et la Sainte Vierge }\end{array}$ & & & & 30000 ans* & & & \\
\hline
\end{tabular}




\begin{tabular}{|c|c|c|c|c|c|c|c|}
\hline & $\begin{array}{l}\text { Congrégation } \\
\text { des filles }\end{array}$ & $\begin{array}{l}\text { Congrégation } \\
\text { de la Vierge }\end{array}$ & $\begin{array}{l}\text { Sainte- } \\
\text { Famille }\end{array}$ & $\begin{array}{l}\text { Sainte- } \\
\text { Anne }\end{array}$ & Rosaire & Scapulaire & $\begin{array}{l}\text { Sacré- } \\
\text { Coeur }\end{array}$ \\
\hline $\begin{array}{l}\text { S'abstenir de viande le mercredi } \\
\text { Réciter quotidiennement } 7 \text { Pater et } 7\end{array}$ & & & & & & $\begin{array}{l}300 \text { jours } \\
40 \text { jours }\end{array}$ & \\
\hline Ave & & & & & & & \\
\hline $\begin{array}{l}\text { Communier mensuellement, avec } 7 \\
\text { Pater et } 7 \text { Ave }\end{array}$ & & & & & & $\begin{array}{l}5 \text { ans et } 5 \\
\text { quarantaines }\end{array}$ & \\
\hline $\begin{array}{l}\text { Communier à la chapelle de la } \\
\text { confrérie aux fêtes de la Vierge avec } \\
7 \text { Pater et } 7 \text { Ave }\end{array}$ & & & & & & $\begin{array}{l}3 \text { ans et } 3 \\
\text { quarantaines }\end{array}$ & \\
\hline $\begin{array}{l}\text { Accompagner la procession du Sca- } \\
\text { pulaire, se confesser et communier } \\
\text { le } 3^{\mathrm{e}} \text { dimanche du mois }\end{array}$ & & & & & & Plénière & \\
\hline $\begin{array}{l}\text { Visiter la chapelle au lieu d'accom- } \\
\text { pagner la procession }\end{array}$ & & & & & & Plénière & \\
\hline $\begin{array}{l}\text { Visiter la chapelle de la confrérie et } \\
\text { réciter } 5 \text { Pater et } 5 \text { Ave aux autels de } \\
\text { l'église }\end{array}$ & & $\begin{array}{l}\text { Ind. des sta- } \\
\text { tions de Rome }\end{array}$ & & & $\begin{array}{l}\text { Ind. des sta- } \\
\text { tions de Rome }\end{array}$ & $\begin{array}{l}\text { Ind. des sta- } \\
\text { tions de Rome }\end{array}$ & \\
\hline 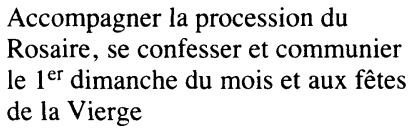 & & & & & Plénière & & \\
\hline $\begin{array}{l}\text { Visiter la chapelle du Rosaire, se } \\
\text { confesser et communier le } 1^{\text {er diman }} \text { - } \\
\text { che du mois, les fêtes des mysteres } \\
\text { du Rosaire et les fêtes de la Vierge }\end{array}$ & & & & & Plénière & & \\
\hline $\begin{array}{l}\text { Réciter chaque Pater et Ave du Cha- } \\
\text { pelet }\end{array}$ & & & & & & & \\
\hline Communier les 15 samedis & & & & & $100 \mathrm{jrs}$ & & \\
\hline Réciter le Rosaire perpétuel & & & & & $100 \mathrm{jrs}$ & & \\
\hline $\begin{array}{l}\text { Assister à la messe pour un confrère } \\
\text { défunt durant l'octave de la Tous- } \\
\text { saint et à chaque lundi }\end{array}$ & & $\begin{array}{r}\text { Plénière } \\
\text { (Pour }\end{array}$ & $\begin{array}{l}\text { Plénière } \\
\text { âmes du }\end{array}$ & $\begin{array}{l}\text { Plénière } \\
\text { purgatoire) }\end{array}$ & & & \\
\hline
\end{tabular}

N.B. Les indulgences des confréries du Rosaire et du Scapulaire étaient applicables aux âmes des fidèles défunts.

* Cette donnée est fort étonnante mais elle figure textuellement dans le «Petit livre des pratiques de dévotion des confréries de Sainte-Anne, du Rosaire et du Scapulaire». 
fiques. La première consistait à accueillir toutes les personnes intéressées de façon à répandre une dévotion le plus largement possible dans la masse populaire. La seconde visait à recruter seulement un groupe déterminé de personnes et à leur prescrire des obligations spécialement adaptées à leur état. Mais ces différents moyens devaient aboutir à une même fin: la sanctification des fidèles.

\section{a - Confréries de dévotion populaire}

Les confréries de dévotion populaire se caractérisaient par le fait que toutes les personnes de l'un et l'autre sexe pouvaient s'y inscrire. Seule condition d'admission: de bonnes moeurs et une bonne réputation. Les exercices de piété demandés étaient généralement simples et peu contraignants.

Dans cette catégorie peuvent se ranger à coup sûr les confréries du Scapulaire, du Rosaire, de Sainte-Anne et du Sacré-Coeur.

\section{1 - Confrérie du Scapulaire de Notre-Dame du Mont-Carmel}

Dans plusieurs confréries, la formule d'engagement comprenait une demande adressée au patron d'assister les affiliés au moment de leur mort. Dans la confrérie du Scapulaire, la recherche de cette protection avait une importance prépondérante.

Selon une tradition remontant au Moyen Age et rapportée par le père de La Colombière ${ }^{9}$, la Vierge aurait promis de préserver de l'enfer les personnes qui porteraient son scapulaire. Le pape Jean XXII ajouta dans la bulle «sabbatine» que la Vierge ferait sortir du purgatoire le samedi après leur mort ceux qui observeraient ces trois conditions: porter le scapulaire jusqu'à la mort, garder la chasteté, observer les jours de jeûne et d'abstinence. Le principal geste de piété extérieur demandé aux membres de cette confrérie consistait donc à porter continuellement sur eux un scapulaire et même à en être revêtu à la mort. Cet objet de dévotion consistait en deux petits carrés de drap sur lesquels étaient inscrits une invocation à la Vierge et parfois son image, et qui se portaient l'un dans le dos et l'autre sur la poitrine, reliés par un cordon. Un deuxième règlement prescrivait une prière spéciale à la Vierge.

Dès 1652 , le père Poncet commença à inscrire le nom des gens qui portaient le scapulaire ${ }^{10}$. Quatre ans plus tard, il fonda la confrérie, assura la célébration des offices mensuels et de la fête annuelle, et Mgr de Laval apporta sa confirmation officielle en $1665^{11}$.

9 Archives du monastère de l'Hôtel-Dieu de Québec (dorénavant AMHDQ), La Colombière, Sermons, II: 221-243. Sermon pour la fête du Scapulaire.

10 Archives de la paroisse Notre-Dame de Québec (dorénavant APNDQ), ms 26. Registre du Scapulaire.

${ }_{11}$ APNDQ, carton 1, no 29. Commission donnée par le père Dequen au père Poncet d'établir la confrérie du Saint-Scapulaire à Québec (15 octobre 1656) et certificat d'érection par le père 


\section{2 - Confrérie du Rosaire}

La confrérie du Rosaire était elle aussi dédiée à la Vierge Marie, mais elle revêtait un caractère nettement différent. Elle visait à inspirer aux fidèles une «dévotion tendre et solide envers les mystères de notre religion et la très sainte Vierge ${ }^{12}$. La récitation du rosaire devait en effet s'accompagner d'une méditation des mystères de la vie de Jésus et de Marie. Ainsi, le culte marial prenait un caractère christocentrique.

Les principales obligations des associés consistaient à réciter une fois par semaine les quinze dizaines de chapelet qui composaient le rosaire et à assister à un office spécial le premier dimanche du mois.

Cette confrérie fit son apparition en Nouvelle-France grâce à une laïque, Marie Favery, qui entreprit les premières démarches auprès des autorités dès $1647^{13}$. Le père Poncet établit la confrérie à Québec neuf ans plus tard ${ }^{14}$ et Marie Favery compléta son oeuvre par une fondation pour la célébration de l'office mensuel et de la fête patronale ${ }^{15}$.

\section{3 - Confrérie de Sainte-Anne}

A l'origine, la confrérie de Sainte-Anne avait été conçue comme une confrérie de métiers ${ }^{16}$. C'est à la demande d'un groupe de menuisiers de Québec que le curé Poncet avait érigé «la confrérie des menuisiers de Sainte-Anne, leur patronne» ${ }^{17}$.

Le même ecclésiastique rédigea aussi les premiers règlements, prescrivant des exercices de piété semblables à ceux des associations

Poncet (ler novembre 1656). APNDQ, carton 1, no 30. Fondation de services religieux et dévotions pour la confrérie du Saint-Scapulaire, devant Audouart, 20 mai 1657. APNDQ, carton 1, no 33. Établissement par Mgr de Laval de la confrérie du Saint-Scapulaire à Québec, 30 août 1665. Document reproduit dans MEQ, I: 66-67.

${ }_{12}$ Archives de la basilique Sainte-Anne-de-Beaupré (dorénavant ABSAB), PA-13, Livre de la Sainte-Famille, du Rosaire et du Scapulaire, 82. Mgr de Saint-Vallier, 4 novembre 1693, «Patentes d'établissement de la confrérie du Rosaire dans la paroisse Sainte-Anne-du-Petit-Cap».

13 Jean-Marie Beauregard, "L'établissement du Rosaire en Nouvelle-France», Société canadienne d' histoire de l'Église catholique. Rapport 1954-1955, 67-88 (dorénavant RSCHEC). APNDQ, carton 1, no 19. «Requête des habitants du Canada adressée au Prieur des Jacobins du Couvent de Saint-Jacques pour obtenir l'établissement de la confrérie du Saint-Rosaire». APNDQ, carton 1, no 20. Copie collationnée du document précédent avec au bas permission de l'archevêque de Paris d'ériger la confrérie du Rosaire à Québec, 21 mai 1649. APNDQ, carton 1, no 21. Lettre patente pour l'établissement de la confrérie du Saint-Rosaire à Québec par le supérieur des Frères Prêcheurs à Paris, 21 mai 1649. APNDQ, carton 1, no 25. Bulle d'indulgences accordée par Innocent X pour la confrérie du Rosaire, 1654.

14 APNDQ, carton 1, no 23. Commission du Père Dequen au Père Poncet, curé de Québec, d'établir la confrérie du Saint-Rosaire à Québec avec au bas l'attestation du père Poncet, 23 septembre 1656 .

15 APNDQ, carton 1, no 24. Fondation de services religieux et de processions pour le SaintRosaire par Marie Favery. Devant Audouart, 22 avril 1657.

16 Marius Barbeau, «La confrérie de Sainte-Anne», Mémoires de la Société royale du Canada, section I, série III, 39 (mai 1945): 1-18. D. Levack, La confrérie de Sainte-Anne à Québec (SainteAnne-de-Beaupré, 1956), 201 p. Archives du Séminaire de Québec (dorénavant ASQ), Documents Faribault, no 96. Supplique des menuisiers au Père Dequen, 1657.

17 ASQ, polygraphie 29. Autorisation par le Père Dequen, 8 avril 1657. ASQ, Documents Faribault, no 96. Décret d'érection de la confrérie Sainte-Anne par le père Poncet, ler mai 1657. 
précédentes, auxquels il ajouta des prières pour les défunts ${ }^{18}$. Diverses bonnes oeuvres étaient prévues, comme l'aumône et les visites aux nécessiteux, en plus de la surveillance des moeurs par les «maîtres de quartiers». Toutefois, ces règlements étaient très mal observés ${ }^{19}$. Mgr de Laval les modifia considérablement en 1678, conservant seulement les pratiques pieuses ${ }^{20}$.

Autre changement d'importance, l'évêque décréta que dorénavant la confrérie serait composée «tant des maîtres menuisiers que d'autres personnes d'honneur et de bonnes moeurs». Comme dans les autres associations, les confrères devaient imiter les vertus de leur patronne. Dans le cas de sainte Anne, l'accent était mis sur son amour de Dieu et du prochain ${ }^{21}$. Finalement, le clergé avait rendu cette confrérie de métiers semblable aux autres confréries de dévotion populaire.

\section{4 - Tiers ordre franciscain}

Le tiers ordre franciscain était affilié à l'ordre des récollets qui l'introduisirent dans la colonie au $17 \mathrm{e}$ siècle ${ }^{22}$. Un sermon du père de la Colombière nous informe que les trois principales obligations des tertiaires consistaient à pratiquer la chasteté, l'humilité et à honorer les saintes plaies de Notre-Seigneur. Les tertiaires devaient également porter sur eux un cordon formé de trois brins qui symbolisaient leurs engagements ${ }^{23}$. Les exercices de piété prescrits aux tertiaires peuvent être reconstitués de façon hypothétique d'après les règlements en vigueur dans la région de Paris. Le deuxième dimanche de chaque mois, ils devaient assister à une messe solennelle, aux vêpres et à une procession dans la chapelle du tiers ordre. Une assemblée hebdomadaire réunissait séparément les frères et soeurs du tiers ordre pour les former à la vie intérieure. A certaines solennités, ils prenaient part aux cérémonies de la messe conventuelle ${ }^{24}$. Les défunts étaient ensevelis dans la chapelle du tiers ordre, revêtus de leur habit ${ }^{25}$.

18 ASQ, polygraphie 29. Statuts de la confrérie de Sainte-Anne par le père Poncet. Copie aux archives de la Basilique Sainte-Anne de Beaupré P - r F, b 1, no 340.

19 Cette note figure sur la copie du document conservée à Sainte-Anne-de-Beaupré.

20 MEQ, 1: 101-103, Règlements et statuts de la confrérie de Sainte-Anne établie dans la paroisse de Québec, 8 octobre 1678. APNDQ, ms 33, Cahier de la confrérie de Sainte-Anne contenant la copie de plusieurs documents, y compris le règlement de 1678 .

21 APNDQ, ms 34, Petit livre des pratiques de dévotion des confréries de Sainte-Anne, du Rosaire et du Scapulaire, s. d., 6

${ }_{22}$ Bienvenu d'Osimo, Notes historiques sur le Tiers-Ordre à Québec, 1678-1902 (Québec, Le Soleil, 1903), 45 p.

23 La Colombière, Sermons, IV: 367-386. Sermon pour la fête du cordon de saint François.

24 Ephrem Longpré, Le Tiers-Ordre séculier de saint François d'Assise au Canada (Montréal, Ménard, 1921), 38-41.

25 ANQ, Greffe de Romain Becquet, 18 juillet 1678. Donation de Jean Gibaut et Suzanne Binet aux récollets. 


\section{5 - Confrérie du Sacré-Coeur}

La dernière confrérie fondée dans la ville de Québec sous le Régime français fut celle du Sacré-Coeur, dans une chapelle du monastère des ursulines ${ }^{26}$. Ce lieu d'implantation se justifiait par le fait que la première supérieure de cette communauté, Marie de l'Incarnation, avait transmis à ses consoeurs sa très grande dévotion au Sacré-Coeur. En 1700 , les ursulines commencèrent à célébrer solennellement la fête du Sacré-Coeur ${ }^{27}$, et seize ans plus tard, les activités de la confrérie débutèrent ${ }^{28}$.

Cette confrérie se distinguait des autres par son caractère de dévotion réparatrice. Elle s'était répandue en Europe après qu'une religieuse visitandine, Marguerite-Marie Alacoque, eût déclaré que le Christ lui avait demandé de prier spécialement pour réparer les outrages faits au Saint-Sacrement. Dans ce but, les associés de la confrérie s'engageaient à passer une heure par année, à date fixe, en adoration devant le SaintSacrement.

Les règlements de la confrérie du Sacré-Coeur et du Scapulaire étaient des plus simples; ceux de Sainte-Anne et surtout du tiers ordre, plus exigeants. Mais ces associations conservaient un caractère commun: elles étaient ouvertes à toutes les personnes des deux sexes qui voulaient participer à la dévotion proposée.

\section{$b$ - Confréries spécialisées}

Contrairement aux confréries de dévotion populaire, les confréries spécialisées ne se proposaient pas un recrutement de masse mais s'adressaient plutôt à un secteur bien particulier de la population: les hommes et les étudiants pour la congrégation de la Vierge, la confrérie de la Sainte-Famille pour les femmes mariées, la congrégation des externes pour les jeunes filles.

Ces trois associations demandaient à leurs membres de viser à la perfection chrétienne dans l'accomplissement de leur devoir d'état, de façon à servir de modèles à leur entourage. Pour cette raison les conditions d'admission et les règlements étaient plus sévères que dans les autres confréries (tableau 2).

\section{1 - Congrégation de la Vierge}

En mettant sur pied leurs congrégations mariales, les jésuites ne se proposaient pas de constituer des effectifs nombreux, mais plutôt de

26 Lionel Lindsay, Les origines de la Dévotion au Sacré-Coeur de Jésus au Canada (Montréal, A.-P. Pigeon, 1900), $71 \mathrm{p}$.

27 MEQ, I: 384-385. Mandement de Mgr de St-Vallier pour établir la fête du Sacré-Coeur de Jésus aux Ursulines de Québec, 30 mars 1700.

28 Archives des Ursulines de Québec (dorénavant AUQ), Registre des personnes qui se sont enrôlées dans la confrérie du Sacré-Coeur de Jésus le 6e jour de juin 1716. 
TABLEAU 2

Exercices de piété prescrits aux différentes confréries

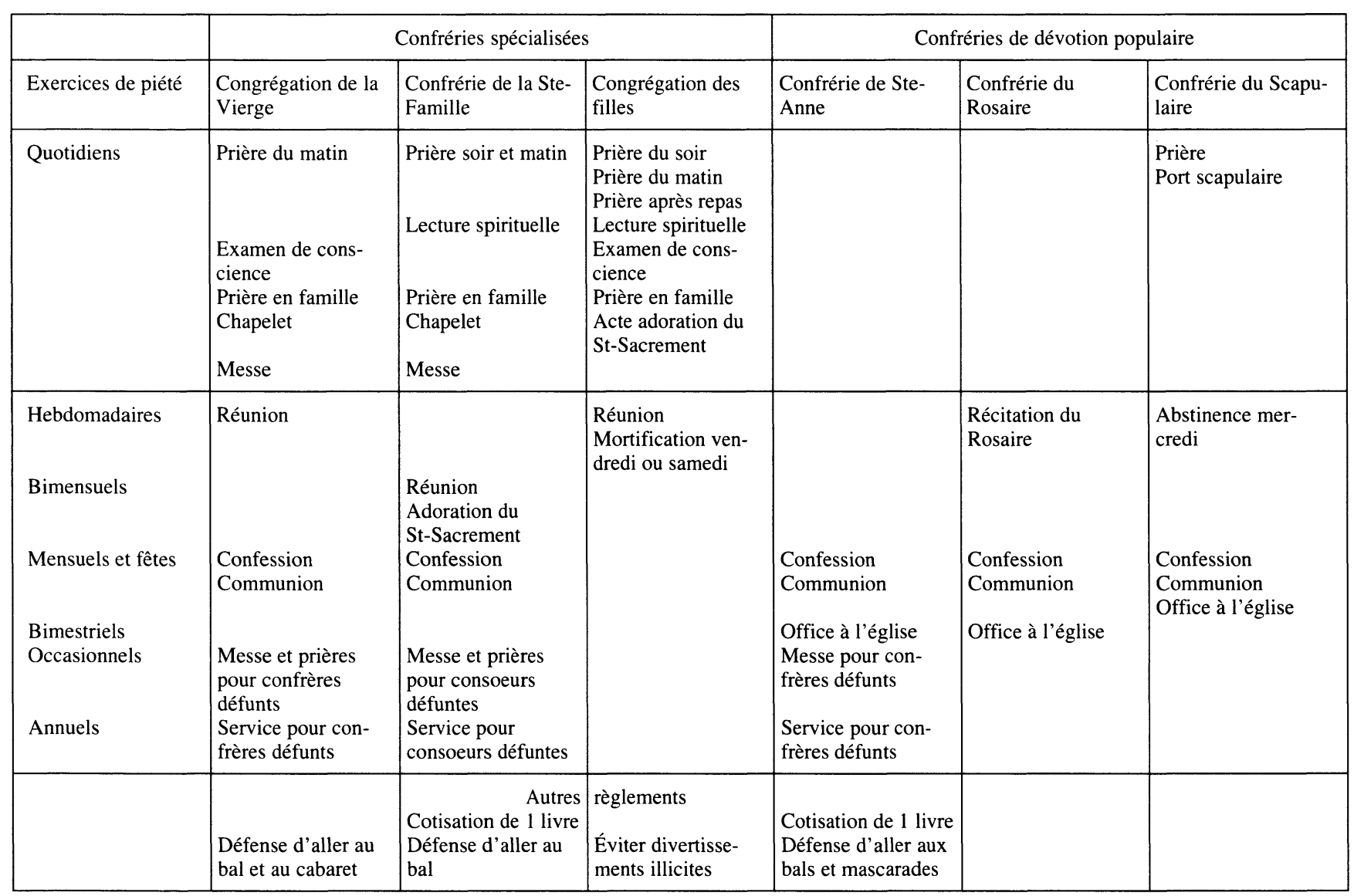


former des groupes d'élite (au sens moral et spirituel du terme) en mesure d'agir efficacement sur la masse ${ }^{29}$. A Québec, ils fondèrent d'abord la Congrégation des Messieurs,en 1657, puis la «Petite Congrégation» destinée aux élèves de leur collège en $1664^{30}$. Les statuts et règlements appliqués sous le Régime français n'ont pu être retrouvés, mais on peut s'en faire une idée d'après ceux existant en France à la même époque.

N'entrait pas qui veut dans la congrégation. Les aspirants devaient d'abord prouver qu'ils dépassaient la simple médiocrité. La période de probation permettait de sélectionner les futurs sujets d'élite: les seuls admissibles ${ }^{31}$.

Une fois admis, les congréganistes devaient accomplir quotidiennement plusieurs exercices de piété (messe, prière, examen de conscience) et assister à une réunion hebdomadaire. A cela s'ajoutaient des activités charitables: prières et convoi funéraire spécial pour les confrères défunts, secours aux pauvres, aux prisonniers et aux malades. Enfin quelques règles de conduite sociale comme l'interdiction de fréquenter les cabarets et les lieux de plaisir. Les manquements sérieux à ces prescriptions pouvaient entraîner l'expulsion.

Les congréganistes devaient donc être des exemples vivants du mode de vie que le clergé attendait des dévôts au $17 \mathrm{e}$ siècle. Comme la congrégation accueillait seulement des hommes, le clergé de la colonie organisa rapidement sur ce modèle des associations destinées aux femmes.

\section{2 - Confrérie de la Sainte-Famille}

La confrérie de la Sainte-Famille naquit à Montréal, en 1663, grâce à l'action de Barbe de Boullongne, veuve du gouverneur Louis d'Ailleboust, et de son confesseur, le jésuite Chaumonot. Par ce moyen, la fondatrice désirait «réformer les familles chrétiennes sur le modèle de la Sainte Famille du Verbe incarné» ${ }^{32}$. Mgr de Laval, grand dévôt de la Sainte-Famille, lui demanda d'organiser la même confrérie à Québec.

Au début, l'association regroupait des personnes des deux sexes. Les hommes étaient dirigés par les jésuites, les femmes, par des dames associées, et les filles, par les ursulines ${ }^{33}$. Par la suite, Mgr de Laval

\footnotetext{
29 Émile Villaret, Les congrégations mariales (Paris, Beauchesne, 1947), 211 et 292.

30 Journal des Jésuites (Montréal, Éditions François-Xavier, 1973), 206 et 329. (Dorénavant $J J$ ).

${ }_{31}$ Émile Villaret, Congrégations de la Sainte-Vierge, Manuel des directeurs (Reims, Impr. du Nord-est, 1930), 450 p.; «Congrégations de la Sainte-Vierge», Dictionnaire de Spiritualité, 2, col. 1482.

${ }_{32}$ Autobiographie du R. P. Chaumonot de la Compagnie de Jésus et son complément par le père Félix Martin (Paris, Poitiers, 1885), 167.

33 Marie de l'Incarnation, Correspondance (dom Oury, éditeur), 735, 19 août 1664.
} 
décida que la Sainte-Famille accepterait seulement les femmes, pour ne pas nuire au recrutement de la congrégation, et il en confia la direction aux prêtres de son Séminaire. Mais l'organisation et les exercices de piété de la nouvelle confrérie furent calqués sur ceux de la congrégation ${ }^{34}$.

L'esprit de cette association consistait à «imiter les sacrées personnes qui composent la Sainte-Famille, chacun selon son état et sa condition ${ }^{35}$. Les hommes devaient donc imiter saint Joseph, les femmes, la sainte Vierge, les enfants, l'Enfant Jésus, et les serviteurs, les saints anges. Le manuel de La Solide Dévotion à la Sainte Famille contient le modèle familial que le clergé proposait à la population de la Nouvelle-France ${ }^{36}$. On y découvre les structures fortement hiérarchisées de la famille sous l'Ancien Régime, les rapports d'autorité tempérés uniquement par la douceur et la charité chrétienne.

A l'homme incombaient tous les devoirs et responsabilités de chef de famille, qui consistaient surtout à inciter, voire à obliger sa femme, ses enfants et ses serviteurs à observer les règles de vie chrétiennes. Aux enfants, on recommandait de pratiquer les mêmes vertus que l'Enfant Jésus, mais surtout l'obéissance «entière, prompte et joyeuse», la chasteté et la modestie ${ }^{37}$. Les serviteurs, considérés à l'époque comme des membres de la famille, devaient faire preuve d'humilité, d'obéissance et de fidélité ${ }^{38}$. Les femmes enfin devaient manifester à leur mari un amour sincère, respect et obéissance, élever leurs enfants dans la crainte de Dieu et surveiller la conduite de leurs serviteurs. En toutes occasions, il fallait qu'elles donnent le bon exemple à leur prochain, notamment en s'abstenant des "plaisirs mondains et profanes», comme les bals, et en observant «la modestie chrétienne dans leurs vêtements et leur conduite» ${ }^{39}$.

Pour entretenir leur dévotion à la Sainte-Famille, les dames de la confrérie devaient accomplir des exercices de piété fort semblables à ceux de la congrégation, mais adaptés à leur condition de mères de famille et maîtresses de maison. Par exemple, le règlement de la confrérie leur recommandait d'entendre la messe à tous les jours, si les soins de leur ménage le leur permettaient, de faire une lecture pieuse en présence des enfants et des domestiques et de réciter le chapelet en famille ${ }^{40}$.

\footnotetext{
34 Chaumonot, op. cit., 170.

35 MEQ, I: 56. «Règlements de la confrérie de la Sainte-Famille».

36 La solide dévotion à la très sainte famille de Jésus, Marie et Joseph, avec un catéchisme qui enseigne à pratiquer leurs vertus (Paris, Florentin Lambert, 1675), 192 p. La tradition attribue ce manuel à Louis Ango des Maizerets. Voir Honorius Provost, «La dévotion à la Sainte-Famille en Canada", Revue de l' Université Laval, 18,5 (janv. 1964): 402.

37 La solide dévotion, 158ss.

38 La solide dévotion, 170.

39 MEQ, I: 60.

40 MEQ, I: 59.
} 
A cela s'ajoutaient des obligations que l'on retrouve également dans d'autres associations comme prier pour les défunts, secourir les malades, quêter pour les pauvres, assister aux réunions bimensuelles et entretenir la chapelle.

Comme on le voit, l'esprit de la Sainte-Famille devait imprégner tous les faits et gestes des personnes associées, dans leur vie personnelle, sociale et surtout familiale. C'est un engagement total que la confrérie exigeait de ses membres.

\section{3 - Congrégation des filles externes}

Comme la confrérie précédente, la congrégation des filles externes apparut d'abord à Montréal. Elle fut fondée en 1658 par les soins de Marguerite Bourgeois ${ }^{41}$. Par la suite, les soeurs de la Congrégation Notre-Dame l'implantèrent dans les paroisses où elles enseignaient à l'intention des «grandes filles qui avaient passé un an après leur première communion ${ }^{42}$. Parmi ces dernières, elles devaient recruter les servantes et les pauvres filles de préférence aux riches ${ }^{43}$, probablement parce qu'elles avaient plus besoin de formation.

Pour être admises dans la congrégation, les adolescentes devaient manifester de bonnes dispositions: éviter la vanité dans leurs habits et leur coiffure, renoncer aux assemblées des hommes et garçons et autres compagnies qui pourraient les scandaliser, se montrer obéissantes à leurs parents, modestes et dévotes à l'église ${ }^{44}$. A partir de cette base, les religieuses leur enseignaient à pratiquer «tout ce que des filles vrayment chrétiennes sont obligées de faire [...] et tâcher d'être l'exemple de toutes les autres» ${ }^{45}$.

Presque tous les règlements de cette congrégation (18 sur 20) concernaient des exercices de piété depuis la prière du matin jusqu'à l'invocation avant de s'endormir en passant par les cantiques spirituels qui devaient accompagner leur travail ${ }^{46}$. Comme les dames de la SainteFamille, elles devaient faire la prière du soir en famille, fuir «les divertissements illicites et les jeux défendus ${ }^{47}$, assister à une réunion hebdomadaire.

La similitude de ces règlements avec ceux de la confrérie de la Sainte-Famille facilitait sûrement le passage de l'une à l'autre associa-

41 Archives de la Congrégation Notre-Dame à Montréal (dorénavant ACND), Dossier 200.100, no 4. Anciens documents historiques sur la Congrégation de Notre-Dame de la Victoire.

42 ASQ, Soeurs de la Congrégation, no 22, 41-42.

43 Ibid.

44 ASQ, soeurs de la Congrégation, no 56. Règlement de la Congrégation des externes.

45 ASQ, Soeurs de la Congrégation, no 19. Règles des filles externes de la Congrégation de la Sainte-Vierge.

46 ASQ, Soeurs de la Congrégation, no 56.

47 Ibid. 


\section{TABLEAU 3}

Répartition des confréries dans les paroisses du Gouvernement de Québec sous le Régime français

Érectiọn canonique de la paroisse

1664. Notre-Dame de Québec

1678. Château-Richer

1678. Saint-Michel de Bellechasse

1678. Sainte-Anne-de-la Pocatière

1678. Berthier-en-bas

1680. Saint-Charles-des-Grondines

1684. L'Ange-Gardien

1684. Sainte-Anne-du-Petit-Cap

1684. Sainte-Famille, Île d'Orléans

1684. Beauport

1684. Neuville (Pointe-aux-Trembles)

1691. Saint-Augustin-de-Desmaures

1693. Saint-Charles-de-Charlesbourg

1694. Rivière-Ouelle, La Bouteillerie

1694. Saint-Nicolas, rive Sud

1694. Saint-Joseph-de-la-Pointe-de-Lévy

1698. Notre-Dame-de-Foy

1698. L'Ancienne-Lorette

1700. Cap-Saint-Ignace, Île-aux-Oies

1702. Saint-Antoine-de-Tilly

1714. Sainte-Famille-du-Cap-Santé

1714. Saint-Jean-Baptiste (Île d'Orléans)

1714. Saint-Étienne-de-Beaumont

1714. Saint-Pierre et Saint-Paul (Île d'Orléans)

1714. Saint-Laurent, Île d'Orléans

1714. Baie-Saint-Paul

1714. Saint-Louis-de-Kamouraska

1714. Saint-Vallier

1714. Saint-François-de-Sales (Île d'Orléans)

1714. Saint-Thomas-de-Montmagny

1721. L'Islet

1721. Saint-Jean-Port-Joli

1721. Sainte-Croix-de-Lotbinière

1721. Saint-Joachim

1721. Petite-Rivière Saint-François

1721. Jeune Lorette

1722. Saint-Roch des Aulnaies

1724. Saint-Louis-de-Lotbinière

1735. Saint-Joseph-de-Deschambault

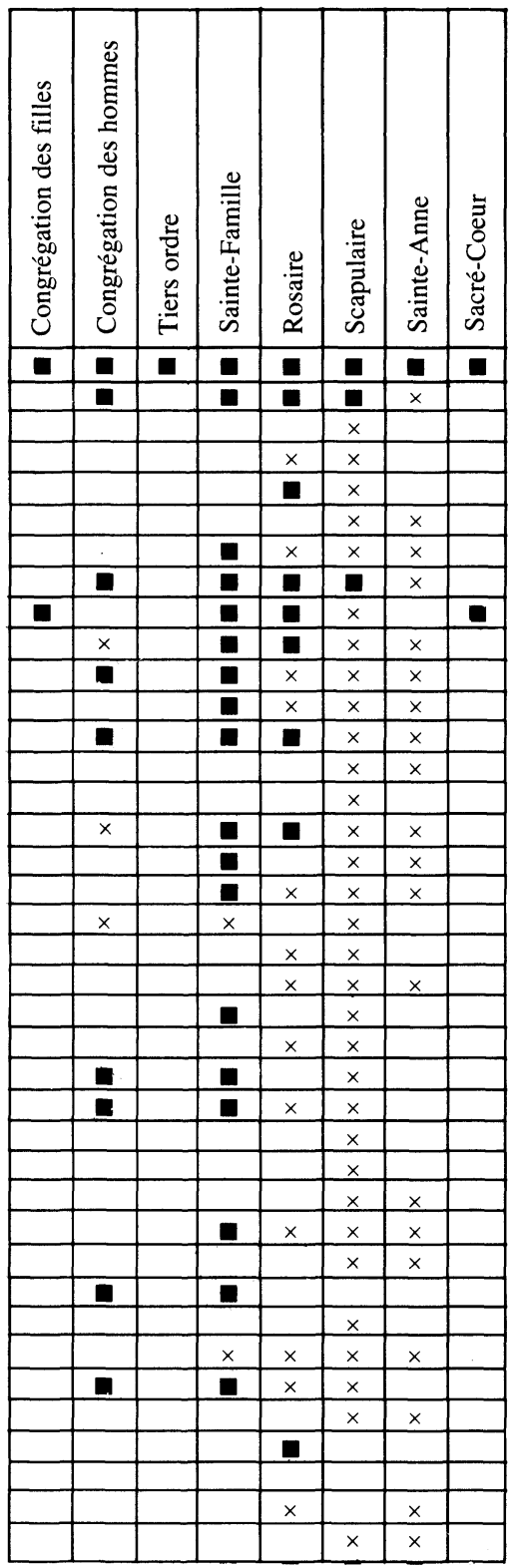


* Sainte-Marie-de-la-Beauce

* Saint-Jean-Baptiste-de-Deschaillons

* Saint-Charles-de-Bellechasse

* Saint-Louis-de-l'Île-aux-Coudres

* Les Éboulements

* Trois-Pistoles

* L'Île-Verte

* Saint-Germain-de-Rimouski

* Les Écureuils

* Rivière-du-Loup

* Saint-Joseph-de-la-Beauce

* Saint-François-de-Montmagny

* Saint-Pierre-de-Montmagny

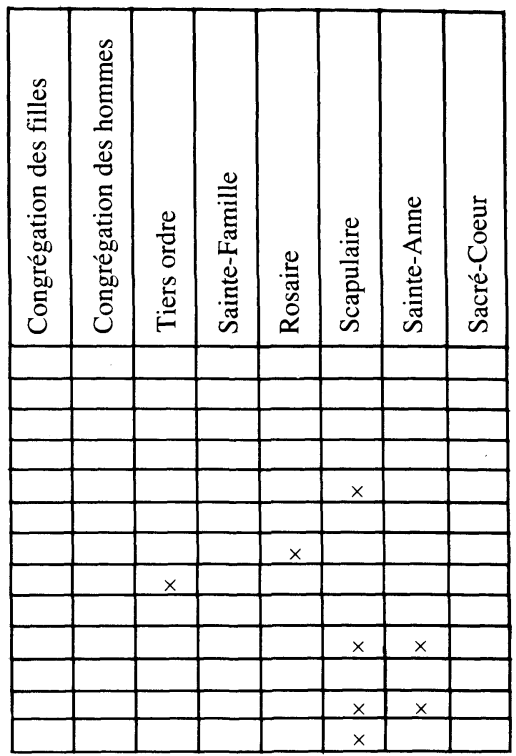

N.B.:

indique que la confrérie était établie dans cette paroisse, avant 1760 .

$\bigotimes$ signifie qu'un ou plusieurs habitants de cette paroisse étaient inscrits dans les registres d'une paroisse voisine, probablement parce que cette confrérie n'était pas établie dans leur paroisse.

Les carreaux restent blancs lorsque aucun document ne révèle la présence d'une confrérie dans cette paroisse, ou l'adhésion des habitants du lieu à la confrérie d'une paroisse voisine.

* Ces 13 paroisses existaient comme entités de peuplement sous le Régime français, mais elles ont reçu leur érection canonique après 1760 seulement.

tion quand les jeunes filles se mariaient. La congrégation préparait bien ces dernières au rôle qu'on attendait d'elles comme épouses et mères de familles.

Toutes les confréries implantées dans le gouvernement de Québec sour le Régime français avaient donc pour but l'amélioration morale et spirituelle de la population. En supervisant les statuts et règlements de ces associations et surtout en interdisant de les modifier sans son auto- 
risation, l'évêque se donnait les moyens d'en préserver l'esprit initial et de prévenir les déviations.

Compte tenu de la diversité des dévotions proposées et des exigences très variables des règlements, on peut penser que la plupart des laïcs étaient en mesure de découvrir une confrérie au moins qui correspondait à leurs goûts et à leurs besoins spirituels. Il reste à savoir comment s'exprimait leur choix.

\section{II - UN RECRUTEMENT FORT INÉGAL}

En fondant des confréries dans la colonie, les évêques invitaient les curés à les établir dans leur paroisse respective, mais en leur laissant la liberté de choisir celles qu'ils préféraient. Les paroissiens étaient également libres d'y adhérer ou pas. Le curé pouvait user à leur endroit de moyens incitatifs mais non contraignants.

\section{$a$ - Répartition géographique des confréries}

Mgr de Saint-Vallier avait dicté à son clergé la ligne de conduite à suivre concernant l'établissement des confréries: selon lui il convenait d'en ériger une par paroisse mais pas davantage «pour ne pas se partager dans tant de dévotions» ${ }^{48}$. Cet avis se justifiait, car à la fin du Régime français comme en 1694, certaines paroisses comprenaient plusieurs confréries et d'autres, comme Saint-Nicolas, aucune, ce que le curé attribuait à la faible population de l'endroit ${ }^{49}$.

Le tableau et la carte de la répartition géographique des confréries à la fin du Régime français ${ }^{50}$ révèlent que les paroisses qui comptaient le plus grand nombre de ces associations étaient les plus anciennes du diocèse comme Notre-Dame de Québec, avec 8 confréries, ChâteauRicher et Sainte-Anne-du-Petit-Cap, avec 4 chacune (tableau 3). Les paroisses où se trouvait au moins une confrérie étaient toutes rassemblées au milieu du gouvernement de Québec, dans un petit quadrilatère qui coïncidait avec le secteur le plus peuplé. Toutefois, l'aire de recrutement de certaines associations dépassait largement ces limites.

Le trait qui ressort le plus de ce dénombrement est la prépondérance incontestable de la confrérie de la Sainte-Famille que l'on retrouve dans 18 paroisses. Formés dans un séminaire dédié à la Sainte-Famille, participant à cette dévotion durant leurs années d'études, les prêtres séculiers la transplantaient ensuite dans les paroisses dont ils avaient la

48 Mgr de Saint-Vallier, «Statuts publiés dans le second synode», 1694, MEQ, I: 138.

49 A. P. Saint-Nicolas, Cahier sans titre contenant un «État du spirituel et du temporel de la paroisse», 1742 .

50 Malgré un dépouillement des archives religieuses qui s'est voulu exhaustif, il demeure probable que le tableau 3 soit incomplet et que des confréries aient existé dans d'autres paroisses même s'il n'en subsiste pas de trace. 
Répartition des confréries

dans les paroisses sous le Régime français

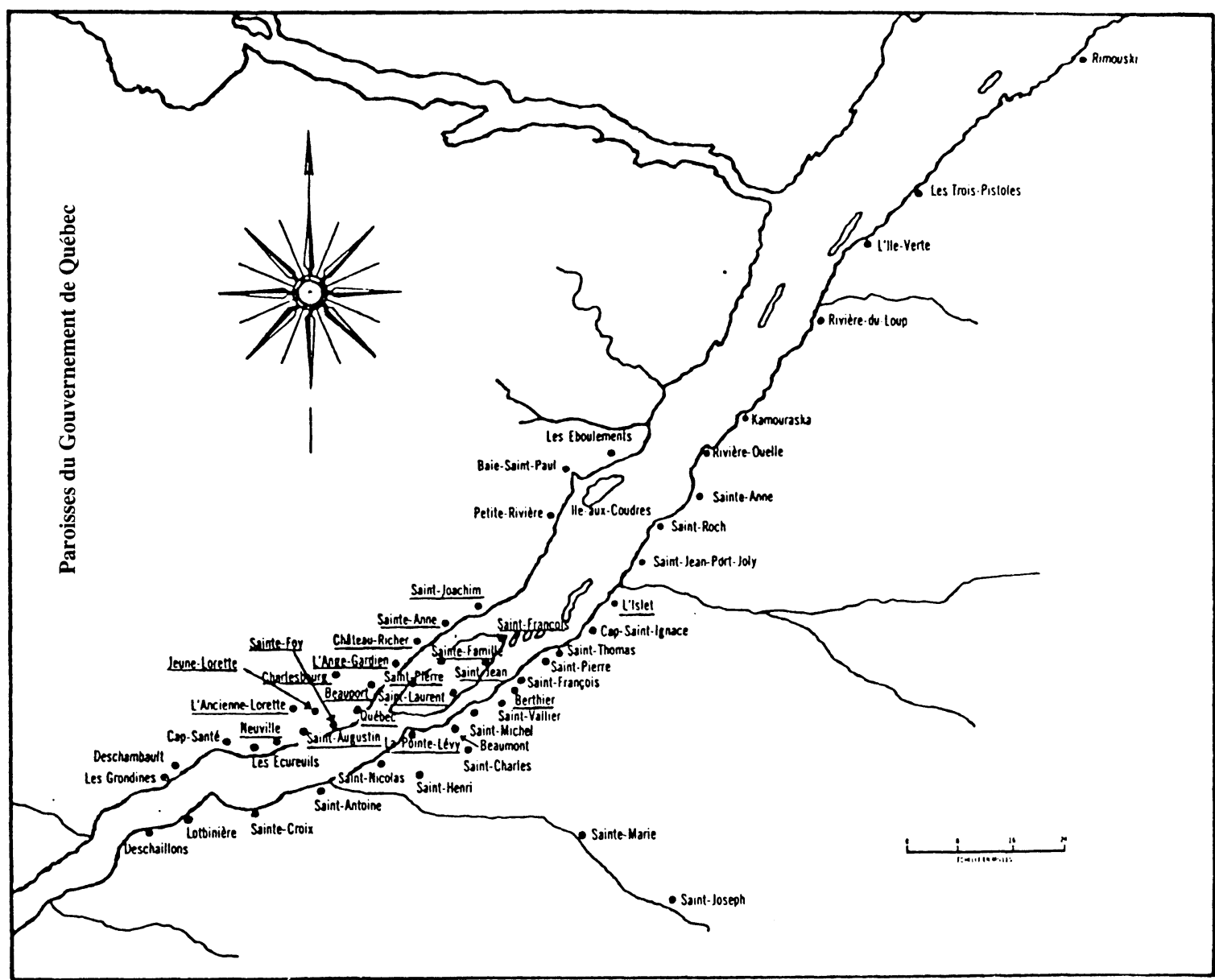

Dans les paroisses dont le nom est souligné, une confrérie au moins a été établie avant 1760.

N.B. Cette carte est tirée du livre de Marcel Trudel, Initiation à la Nouvelle-France, p. 128. 
charge. La présence au second rang de la congrégation de la Vierge et de la confrérie du Rosaire, dans 9 paroisses chacune, montre l'importance que le clergé attachait à ces formes de la dévotion mariale.

Les autres confréries semblent moins répandues. Outre les lacunes des sources, cela peut s'expliquer par différentes raisons: le tiers ordre franciscain devait avoisiner un couvent de récollets, la confrérie du Sacré-Coeur fut fondée à une date tardive (1716) et la congrégation des filles ne pouvait exister que là où les Soeurs de la Congrégation étaient établies. D'autre part, les confréries du Scapulaire et de Sainte-Anne étendaient leur recrutement jusqu'aux confins de la colonie. Cela signifie que même si les curés privilégiaient certaines associations, les habitants qui ne trouvaient pas chez eux une confrérie à laquelle ils tenaient beaucoup avaient toujours la ressource de se joindre à celle d'une paroisse voisine.

\section{$b$ - Composition des confréries}

Comme les confréries étaient destinées à animer la dévotion populaire, on peut s'attendre à y retrouver des gens de tous les âges et de tous les milieux sociaux. Toutefois de nombreux facteurs, pas seulement religieux, pouvaient influencer le mode de recrutement et le choix des membres du conseil de direction.

\section{1 - Recrutement des confréries}

En principe, l'entrée dans une confrérie constituait un geste de dévotion laissé à la discrétion des fidèles. Mais les règlements de quelques maisons religieuses prévoyaient que leurs employés ou leurs élèves devaient s'inscrire à certaines de ces associations. Les domestiques «donnés» du Séminaire de Québec, par exemple, devaient s'affi-

TABLEAU 4

Nombre d'adhérents aux confréries

des débuts à 1760

\begin{tabular}{|lcrcc|}
\hline & Québec & $\begin{array}{c}\text { Château- } \\
\text { Richer }\end{array}$ & $\begin{array}{c}\text { Ste-Anne-du } \\
\text { Petit-Cap }\end{array}$ & Total \\
\hline Scapulaire & 5171 & 1506 & 970 & 7647 \\
Rosaire & 1095 & 315 & 46 & 1456 \\
Sainte-Famille & 1363 & 22 & 73 & 1458 \\
Sacré-Coeur & $\begin{array}{c}3098 \\
+74\end{array}$ & & & \\
Congrégation & $\begin{array}{c}\text { (incomplet) } \\
+1690\end{array}$ & & & \\
Sainte-Anne & (incomplet) & & & \\
&
\end{tabular}


lier à la confrérie de la Sainte-Famille ${ }^{51}$, et les élèves du Petit Séminaire, s'associer à celles du Rosaire et du Scapulaire ${ }^{52}$. La petite congrégation enfin était destinée spécialement aux étudiants du collège des Jésuites.

En dehors de ces règlements, bien d'autres raisons pouvaient entrer en ligne de compte pour expliquer les écarts considérables entre les effectifs de chaque confrérie. Ceux-ci ont pu être reconstitués pour trois paroisses $^{53}$.

\section{TABLEAU 5}

Répartition des membres des confréries selon leur sexe

dans le Gouvernement de Québec sous le Régime français

\begin{tabular}{|lcccc|}
\hline & $\begin{array}{c}\text { Masculin } \\
\mathrm{N} \%\end{array}$ & $\begin{array}{c}\text { Féminin } \\
\mathrm{N} \%\end{array}$ & $\begin{array}{c}\text { Inconnu } \\
\mathrm{N}\end{array}$ & $\begin{array}{c}\text { Total } \\
\mathrm{N}\end{array}$ \\
\hline N.-D. de Québec & & & & \\
Scapulaire & $47,2 \%$ & $51 \%$ & $1,8 \%$ & \\
Sainte-Anne & $30,3 \%$ & $69,7 \%$ & & \\
Sacré-Coeur & $19,6 \%$ & $80,4 \%$ & & \\
Rosaire & $45,2 \%$ & $52,9 \%$ & $1,9 \%$ & \\
\hline Sainte-Anne du & & & & \\
Petit Cap & & & & \\
Scapulaire & $43,4 \%$ & $56,6 \%$ & & \\
Rosaire & $24 \%$ & $76 \%$ & & \\
\hline Château-Richer & & & & \\
Scapulaire & $43,3 \%$ & $56,7 \%$ & & \\
Rosaire & $21,8 \%$ & $78,2 \%$ & & \\
\hline
\end{tabular}

Aux trois endroits, la confrérie du Scapulaire attirait beaucoup plus de monde que n'importe quelle autre association. Sans doute les personnes recrutées en dehors de la paroisse contribuaient à gonfler les effectifs, mais même si on retient uniquement les personnes résidant dans la paroisse d'origine, les proportions restent sensiblement les mêmes. On constate sans surprise que cette confrérie destinée à un recrutement mixte accueillait plus de membres que la Sainte-Famille

\footnotetext{
51 ASQ, Séminaire 95, no 28. «Reigles communes des Domestiques donnés du Séminaire de Québec», règle $X$.

52 ASQ, ms 239. «Très ancien règlement du Petit Séminaire de Québec», 105, 149, 150.

53 Tous les calculs qui suivent ont été faits d'après les registres suivants: APNDQ, Ms 26, Registre du Scapulaire: 1652-1745; Ms 27, Registre du Scapulaire: 1745-1760; Ms 28, Registre de la Sainte-Famille: 1664-1763; Ms 35, Registre du Rosaire: 1656-1760. ASQ, Registre de Sainte-Anne: 1686-1731; Liste des membres en 1759. AUQ, Registre de la confrérie du SacréCoeur: 1716-1760. AP, Château-Richer, Registre de la Sainte-Famille: s. d.; Registre du Rosaire: 1693-1760; Registre du Scapulaire: 1665-1760. Archives Sainte-Anne-de-Beaupré, Registre de la Sainte-Famille: 1665-1760; Registre du Scapulaire: 1680-1760; Registre du Rosaire: 1693-1760.
} 
TABLEAU 6

Proportion de femmes et filles

dans les confréries de Montréal et Trois-Rivières

des débuts à 1760

\begin{tabular}{|llc|}
\hline Ville & Confrérie & \% de femmes et filles \\
\hline \multirow{2}{*}{ Montréal } & Bonne-Mort & $92 \%$ \\
& Sainte-Trinité & $77,4 \%$ \\
\multirow{2}{*}{ Trois-Rivières } & Sacré-Coeur & $92,7 \%$ \\
& Scapulaire & $68,5 \%$ \\
\hline
\end{tabular}

réservée aux femmes. Il est un peu plus surprenant de constater sa disparité avec la confrérie du Rosaire dédiée elle aussi à la Vierge et ouverte aux personnes des deux sexes. Visiblement, le souci d'éviter l'enfer en se plaçant sous la protection de la Vierge était très répandu chez la population. Quant à la dévotion au Rosaire qui consistait à méditer sur les mystères de la religion, elle présentait des exigences plus grandes et un caractère plus abstrait qui la rendaient moins accessible aux gens du peuple.

Autre disparité frappante, celle qui existe entre les recrues laïques de chaque sexe (tableau 5). Un sondage effectué à Montréal et TroisRivières confirme d'ailleurs cette prépondérance féminine dans les associations pieuses (tableau 6) ${ }^{54}$.

A la campagne comme à la ville, et à la grandeur du Canada, les femmes étaient donc fortement majoritaires dans toutes les confréries. L'écart se réduit cependant dans le cas du Scapulaire. En outre, une comparaison entre le $17 \mathrm{e}$ et le $18 \mathrm{e}$ siècle révèle que ce trait caractérise surtout la deuxième partie du Régime français (tableau 7).

L'infériorité numérique de l'élément féminin dans la colonie au $17 \mathrm{e}$ siècle ${ }^{55}$ explique la moindre proportion de femmes dans plusieurs confréries. Au début du $18 \mathrm{e}$ siècle, l'équilibre des sexes tendit à se rétablir et les femmes acquirent une forte majorité dans toutes les asso-

54 Le tableau 6 a été fait à partir des registres suivants: Archives de Saint-Sulpice, Montréal, A2/E1/3G/1, Catalogue de la Confrérie de la Bonne mort, 1732-1763. Archives de l'Hôtel-Dieu de Montréal, Registre de la confrérie de la Sainte-Trinité, 1720-1760. Archives des Soeurs Grises de Montréal, Catalogue des noms des associés de la confrérie du Sacré-Coeur de Jésus, 17491760. Archives de l'évêché de Trois-Rivières, Registre de la confrérie du Saint-Scapulaire de la bienheureuse Vierge Marie du Mont-Carmel, érigée en 1665. Les recherches à Montréal et TroisRivières ont été effectuées par notre collègue Yves Beauregard que nous remercions de sa collaboration.

${ }_{55}$ Jacques Henripin, La population canadienne au début du XVIIIe siècle. Nuptialité, fécondité, mortalité infantile (Paris, Presses universitaires de France, 1954), 19. Hubert Charbonneau, Vie et mort de nos ancêtres (Montréal, Presses de l'Université de Montréal, 1975), 41. 
TABLEAU 7

Féminisation des confréries au $18^{\mathrm{e}}$ siècle

\begin{tabular}{|clcc|}
\hline Paroisse & Confrérie & \multicolumn{2}{c|}{$\%$ des effectifs féminins } \\
& & des débuts à 1700 & $1701-1760$ \\
\hline Notre-Dame Québec & Scapulaire & 31,8 & 64,8 \\
& Sainte-Anne & 59,9 & 72 \\
& Sacré-Coeur & & 80,4 \\
& Rosaire & 40,4 & 63,7 \\
Ste-Anne-Du-Petit-Cap & Scapulaire & 41,7 & 60,9 \\
& Rosaire & & 76 \\
Château-Richer & Scapulaire & 50,2 & 60,8 \\
& Rosaire & & 78,2 \\
\hline
\end{tabular}

ciations. Le même phénomène a été constaté dans certains diocèses de France sans que la cause ressorte avec évidence ${ }^{56}$.

Un élément d'explication peut être avancé. A cette époque, la sphère d'activité dévolue aux femmes se limitait habituellement aux besognes domestiques et aux soins des enfants. Seule une minorité exerçait un métier ou une profession. En outre, les femmes ne pouvaient pas s'offrir, comme leur mari, la distraction de fréquenter le cabaret. L'inscription à une confrérie leur fournissait l'occasion de quitter quelquefois leur maison pour assister aux offices, aux assemblées et aux services funéraires, visiter les pauvres et les malades. C'étaient d'ailleurs les seules sorties que le clergé approuvait.

A côté de ces traits communs à la ville et à la campagne, certaines particularités de la composition des confréries pouvaient découler de leur situation géographique. D'abord, l'étendue de leur zone de recrutement. Tandis que les confréries de Château-Richer et Sainte-Annedu-Petit-Cap recevaient principalement les habitants des régions limitrophes (l'île d'Orléans et la côte de Beaupré), celles de Québec, situées à un endroit plus central, accueillaient beaucoup plus de résidents des rives Nord et Sud, de Montréalais et même d'Acadiens. On relève même, dans les registres des confréries de Notre-Dame de Québec, des noms de Noirs, d'Indiens et d'Européens, principalement des Français. Dans ce dernier cas, il s'agissait surtout de marins et de voyageurs, mais les

56 Louis Pérouas, Le diocèse de La Rochelle de 1648 à 1724. Sociologie et pastorale (Paris, SEPVEN, 1964), 205-206; "Clergé et peuple creusois du XVe au XXe siècle», dans Histoire vécue du peuple chrétien, Jean Delumeau, dir. (Toulouse, Privat, 1979), 138-139. Jean-Claude Schmitt, «Apostolat mendiant et société. Une confrérie dominicaine à la veille de la Réforme», Annales ESC, 26,1 (janvier-février 1971): 83-104. Jean de Viguerie, «Quelques aspects du catholicisme des Français au XVIIIe siècle», Revue historique, 538 (avril-juin 1981): 337-371. F. Poirault, «La confrérie de l'Assomption de Saumur, 1402-1903», Annales de Bretagne et des Pays de l'Ouest, 86,3 (1979): 405-425. Gabriel Le Bras, Études de sociologie religieuse (Paris, Presses universitaires de France, 1957), 356-358. 
confréries de la Sainte-Famille et du Sacré-Coeur concluaient également des alliances spirituelles avec des laïcs et des religieuses de France.

Capitale administrative de la colonie, la ville de Québec était également le siège des principales maisons d'éducation et de plusieurs communautés religieuses. Ces trois caractéristiques se répercutaient sur la composition des confréries, notamment par l'inscription d'un grand nombre de prêtres et de religieuses qui ne se comptaient qu'à l'unité dans les confréries de la côte de Beaupré.

La présence à Québec de plusieurs maisons d'enseignement se faisait également sentir. Régulièrement, on voyait apparaître dans les livres du Rosaire et du Scapulaire des listes de noms de garçons ou de filles âgés d'une douzaine d'années. Leur inscription coïncidait probablement avec leur première communion. Les élèves des ursulines, de leur côté, adhéraient massivement à la dévotion au Sacré-Coeur. Il en résulte que la proportion des jeunes recrues (celles âgées de moins de 20 ans) était plus considérable à la ville qu'à la campagne, et ce pour toutes les confréries ${ }^{57}$.

Il n'était jamais trop tard cependant pour poser ce geste pieux. Quelques femmes se firent admettre dans la confrérie de la SainteFamille alors qu'elles étaient à l'article de la mort et les premiers membres de la confrérie du Rosaire firent inscrire des personnes décédées dans les registres ${ }^{58}$. La seule utilité de ce geste était de faire gagner des indulgences aux agonisants et aux défunts, et de leur permettre de bénéficier des prières des confrères vivants. Ces cas extrêmes montrent bien l'importance qu'on pouvait attacher aux prières pour les morts.

En principe, les confréries étaient ouvertes aux gens de tous les milieux sociaux. Un rapide coup d'oeil jeté sur la liste des membres nous apprend qu'un esclave pouvait s'y inscrire aussi bien qu'un évêque ou un gouverneur de la Nouvelle-France. Une recherche systématique de la situation socio-professionnelle des personnes associées est plus fiable que la comparaison de ces cas extrêmes, même si la marge d'in-

57 L'âge et le milieu socio-professionnel des personnes au moment de leur entrée dans une confrérie ont été repérés au moyen des ouvrages suivants: Cyprien Tanguay, Dictionnaire généalogique des familles canadiennes (Québec, Eusèbe Sénécal, 1871), 7 volumes. Marcel Trudel, La population du Canada en 1663 (Montréal, Fides, 1973), 368 p. Recensement de Québec en 1744, Rapport de l'archiviste de la province de Québec, 1939-1940, 1-54. Recensement général de 1666, idem., 1935-1936, 1-154. Recensement général de 1681 dans B. Sulte, Histoire des Canadiens français, v, 53-90. Dictionnaire biographique du Canada, vol. 1 à 3 . Nous avons cherché ces 2 informations pour tous les associés des confréries de la Sainte-Famille, du Rosaire et de Sainte-Anne. Nous nous sommes contentée d'un échantillonnage pour les confréries du SacréCoeur (1/3 des membres), du Scapulaire à Québec (1/4 des membres) et du Scapulaire à SainteAnne-du-Petit-Cap (1/2 des membres)

58 APNDQ, Ms 28, Registre de la Sainte-Famille, 26-27. APNDQ, Ms 35, Registre du Rosaire, 30. 
connu qui varie entre 23 et $50 \%$ selon les associations empêche d'atteindre une certitude absolue ${ }^{59}$.

La surreprésentation des notables et de leur famille dans les confréries de Québec peut s'expliquer par deux facteurs au moins: d'abord la présence dans leurs rangs des élèves du Petit Séminaire et des ursulines qui appartenaient en grande partie aux bonnes familles de la colonie; ensuite, le fait que la plupart des gens que nous considérons comme des notables (administrateurs, hauts fonctionnaires, maîtres de métier, hommes d'affaires) résidaient dans la ville de Québec plutôt qu'à la campagne. Dans les confréries de la côte de Beaupré et de l'île d'Orléans, la proportion de notables se rapproche beaucoup plus de celle qui existait véritablement dans la paroisse. Ces associations pieuses épousaient donc les contours sociaux des communautés où elles s'inséraient. Mais peut-être les notables faisaient-ils davantage sentir leur présence à un autre niveau, comme celui de la direction des confréries.

TABLEAU 8

Proportion de notables

dans les confréries urbaines et rurales

sous le Régime français

\begin{tabular}{|lcc|}
\hline & Québec & Sainte-Anne-du-Petit-Cap \\
\hline Sainte-Famille & $36,1 \%$ & $4,1 \%$ \\
Rosaire & $30,1 \%$ & $6,5 \%$ \\
Scapulaire & $20,7 \%$ & $2,7 \%$ \\
Sainte-Anne & $17,2 \%$ & \\
\hline & Québec & Sainte-Famille I.O. \\
\hline Sacré-Coeur & $31,3 \%$ & $6,2 \%$ \\
\hline
\end{tabular}

\section{2 - Conseil de direction}

Toutes les confréries relevaient de l'autorité d'un ecclésiastique, mais trois d'entre elles élisaient également un conseil de direction: la congrégation de la Vierge, les confréries de Sainte-Anne et de la SainteFamille. Les règlements ne formulaient aucune exigence particulière concernant la situation socio-professionnelle des dirigeants, leur âge ou leur expérience au sein de la confrérie, mais on peut se demander jusqu'à quel point ces facteurs entraient en considération.

59 Pour les besoins de cette analyse, nous avons divisé la population en trois catégories: notables, gens du peuple et ceux de métier inconnu. Nous considérons comme des notables les hommes (et leur famille) qui occupaient un poste d'autorité (administrateurs, hauts fonctionnaires, officiers de justice supérieurs, officiers militaires), possédaient une fortune supérieure à la moyenne (entre autres les marchands-bourgeois), une compétence professionnelle reconnue (les maîtres de métier, les médecins, architectes, etc.) ou qui détenaient un titre honorifique comme celui de seigneur, syndic ou capitaine de milice. 
La liste malheureusement incomplète de 26 officiers de la congrégation de Québec ${ }^{60}$ contient uniquement des noms de notables: 11 sont des seigneurs, 8 des membres du Conseil souverain, 12 des marchandsbourgeois. Leur âge, qui varie de 28 à 67 ans, ne semble pas avoir influencé leur nomination. Plusieurs se signalèrent par des activités pieuses et charitables: quatre d'entre eux dirigèrent le Bureau des Pauvres et l'Hôpital-Général, Charles de Lauzon devint prêtre, Paul Dupuy de Lisloye rassemblait ses censitaires au manoir seigneurial, le dimanche, pour leur faire une exhortation pieuse ${ }^{61}$, François Hazeur et Aubert de La Chesnaye comptaient parmi les principaux bienfaiteurs des communautés religieuses. La situation sociale et les activités pieuses de ces gens les amenaient donc tout naturellement aux postes de direction de la congrégation et des organismes de bienfaisance de la ville de Québec.

La liste également partielle du conseil de direction de la SainteFamille $^{62}$ révèle que toutes les supérieures (mesdames d'Ailleboust, Bourdon, Roussel, Courval, de Vaudreuil, à Québec; Feltz et d'Youville à Montréal) et la moitié des conseillères étaient des épouses de notables. Les électrices semblent donc avoir été sensibles à la question du prestige social. Madame de Vaudreuil aurait-elle été nommée supérieure honoraire en 1755 si elle n'avait été l'épouse du gouverneur?

D'autres facteurs pouvaient entrer en ligne de compte au moment de ces nominations. Toutes les supérieures avaient un âge respectable et, de 1744 à 1760, l'âge moyen des membres du conseil était de 59 ans. Ajoutons à cela que les élues appartenaient à la confrérie depuis 22 ans, en moyenne. Cette ancienneté permettait à certaines dames d'acquérir de l'expérience dans les différentes fonctions du conseil avant d'accéder au rang de supérieure.

Comme les dirigeants de la congrégation, quelques-unes des supérieures de la Sainte-Famille se distinguèrent par leur vie édifiante: la réputation de sainteté de madame d'Youville n'est plus à faire; l'épouse du gouverneur de Vaudreuil était elle aussi «portée à la dévotion», selon le témoignage de Montcalm ${ }^{63}$. Quant aux deux premières supérieures, madame d'Ailleboust et madame Bourdon, elles étaient «un exemple de piété et de charité dans tout le pays», allant ensemble visiter les prisonniers et assister les criminels condamnés à mort ${ }^{64}$.

60 Cette liste, qui figure dans notre thèse page 375 , a été dressée à partir des sources suivantes: ANQ, Greffe de Chambalon, 6 août 1699 , constitution de rente des Jésuites pour la grande congrégation de Québec pour l'huile de la Lampe; 8 mars 1700, constitution de rente du sieur de Lino à la grande congrégation. Greffe de Genaple, 16 mars 1695, fondation de messes par les membres de la congrégation. Greffe de Lanouiller, 29 novembre 1750, marché conclu entre les officiers de la congrégation et Pierre-Noël Levasseur. JJ, 206.

${ }_{61}$ Françoise Juchereau et Marie-Andrée Duplessis, Annales de l'Hôtel-Dieu de Québec, 1636-1716 (Montréal, Presses de Garden City, 1939), 337 (dorénavant AHDQ).

62 APNDQ, Ms 28, Registre de la confrérie de la Sainte-Famille.

63 Louis-Joseph de Montcalm, Journal du marquis de Montcalm durant ses campagnes en Canada de 1756 à 1759, l'abbé Henri Casgrain, dir. (Québec, Demers et Frère, 1895), 154.

64 Marie de l'Incarnation, Correspondance, 833, octobre 1668. 
Les responsables de la confrérie de Sainte-Anne ne se signalèrent pas à l'attention de leurs contemporains comme ceux des deux autres associations. Nous savons que l'âge moyen des marguilliers (appelés aussi maîtres-confrères) était de 50 ans et qu'ils appartenaient à la confrérie depuis une quinzaine d'années ${ }^{65}$. La moitié d'entre eux peuvent être considérés comme des notables mais d'un milieu moins huppé que les dirigeants de la Congrégation: il s'agit habituellement de maîtres dans leur métier.

Seuls des hommes figuraient parmi les dirigeants de cette confrérie, même si les femmes constituaient $72 \%$ des effectifs au $18 \mathrm{e}$ siècle. Ces messieurs tenaient-ils à préserver l'ancien aspect de confrérie de métiers de leur association?

L'âge et l'expérience constituaient donc des atouts majeurs pour accéder à un poste de direction dans les confréries de Sainte-Anne et de la Sainte-Famille. Le niveau social jouait un rôle, lui aussi: prépondérant dans le cas des dirigeants de la congrégation et de la SainteFamille, moins accentué pour la confrérie de Sainte-Anne.

\section{3 - Fluctuations du recrutement}

Fondées au début du Régime français, les confréries restèrent en activité jusqu'à la Conquête (et même au-delà) et les conditions d'admission ne changèrent pas. Leur recrutement connut cependant des hauts et des bas en l'espace d'un siècle.

L'attrait de la nouveauté et l'éloquence du curé contribuaient à amener un grand nombre de personnes dans les rangs d'une confrérie au moment de sa fondation. En 1739, le curé Dufrost, de la SainteFamille de l'île d'Orléans, inscrivit dans la confrérie du Sacré-Coeur 208 de ses paroissiens. En 1656, 102 personnes entrèrent d'un seul coup dans la confrérie du Rosaire de Québec. Il va sans dire que dans les années suivantes, le recrutement diminuait forcément faute de nouvelles personnes à admettre.

Un danger imminent pouvait également provoquer un regain de piété dans la population. En 1665 , plus de 500 soldats du régiment de Carignan prirent le scapulaire ${ }^{66}$. En 1690, lors du siège de Québec, les miliciens s'empressaient de se procurer ces «passeports de l'Immaculée-Conception», surnom donné aux scapulaires parce qu'ils étaient censés faciliter l'entrée au ciel ${ }^{67}$. En 1745 et 1746, après la prise de Louisbourg, et en 1756 et 1757, au plus fort de la guerre de Sept Ans, le recrutement de cette confrérie s'éleva de façon exceptionnelle.

65 APNDQ, Ms 33, Cahier de la confrérie de Sainte-Anne.

66 Marie de l'Incarnation, Correspondance, 755, 30 septembre 1665.

67 Catherine Burke et George Lemoine, Les Ursulines de Québec depuis leur établissement jusqu'à nos jours (Québec, Darveau, 1878), I: 440. 
D'autres fluctuations de recrutement s'expliquent plus difficilement. Après des débuts prometteurs, la confrérie du Rosaire de Château-Richer connut une chute brutale des admissions, tandis qu'à SainteAnne-du-Petit-Cap, la même association s'étiolait littéralement. Désintérêt de la part du curé ou indifférence de la population? L'état des sources ne permet pas de répondre à cette question.

D'autres confréries de dévotion populaire (Sainte-Anne, SacréCoeur et Scapulaire) maintenaient presque constamment leur recrutement à un niveau élevé. Dans le cas de cette dernière, la régularité des inscriptions ajoutée à leur nombre élevé et à leur recrudescence en cas de guerre prouvent abondamment le souci des catholiques de l'époque de «faire une bonne mort».

Mais il ne suffisait pas de s'inscrire à une ou plusieurs confréries pour manifester sa dévotion. Encore fallait-il en observer les règlements.

\section{III - DES ACTIVITÉS HABITUELLEMENT ÉDIFIANTES}

L'étude des activités des personnes associées permet de mesurer de façon plus précise le rôle que ces associations ont vraiment joué dans la vie religieuse de la colonie.

Il est naturellement impossible de mesurer les progrès spirituels accomplis par les congréganistes ou les confrères, mais on peut relever leurs gestes extérieurs, pieux ou charitables, leur façon d'observer les règlements et la manière dont les ecclésiastiques remplissaient leurs fonctions de directeurs.

\section{$a$ - Les dames de la Sainte-Famille}

La confrérie de la Sainte-Famille naquit dans une atmosphère de piété accompagnée même de quelques miracles considérés par les contemporains comme une preuve que cette nouvelle dévotion était agréable à Dieu ${ }^{68}$. Une fois passé l'enthousiasme des débuts, la ferveur des dames associées connut des hauts et des bas, comme le recrutement.

Les personnes responsables de la confrérie s'occupaient de l'entretien de la chapelle et payaient annuellement un service pour les consoeurs défuntes. Mais moins de la moitié des membres payaient leur cotisation annuelle et le curé Récher se plaignait, vers 1750, du manque d'assiduité des dames aux assemblées et aux messes pour les défunts, déplorant que la ferveur des débuts ait tellement diminué ${ }^{69}$. En deux circonstances, toutefois, elles firent preuve d'une piété exceptionnelle: lors du siège de Québec, en 1690, et au moment de l'invasion de Walker

68 Marie de l'Incarnation, Correspondance, 755-756, 30 septembre 1665. RJ, 50: 48-52.

69 APNDQ, Ms 30, Cahier de la confrérie de la Sainte-Famille. 
en 1711. Neuvaines, messes, communions, mortifications et aumônes: elles ne négligèrent rien pour se gagner l'appui du Ciel ${ }^{70}$.

En plus de ces pratiques de piété, les dames de la Sainte-Famille assumaient certaines fonctions charitables. Elles quêtaient pour les pauvres et secouraient les personnes dans le besoin, notamment les femmes enceintes. En 1731, madame Regnard Duplessis légua à la supérieure de la confrérie un matelas, des couvertures et des serviettes «pour les prêter aux pauvres femmes qui accouchent, les priant de les retirer avec soin afin de les faire servir et d'en aider plusieurs ${ }^{71}$. A Montréal, madame d'Youville fit son apprentissage de dame de charité au sein de cette confrérie avant de se charger de l'Hôpital-Général.

Plus que par leurs bonnes oeuvres, les dames de la Sainte-Famille firent parler d'elles à cause de leur implication (ou de leur absence) dans la vie mondaine de la colonie.

Les règlements de la confrérie leur interdisaient absolument d'aller aux bals, danses et assemblées de nuit parce qu'elles devaient pratiquer les vertus chrétiennes plus parfaitement que les autres femmes. Quelques-unes l'oublièrent et participèrent aux bals donnés à Québec durant l'hiver 1667. Mécontent, Mgr de Laval suspendit temporairement les réunions de la confrérie, ce qui souleva l'indignation de l'intendant Talon ${ }^{72}$. Le même incident se renouvela vers 1693, 1694. Après avoir fait jouer Nicomède et Mithridate ${ }^{73}$, Frontenac fit préparer Tartuffe et il invita plusieurs dames de Québec à y assister. Toutes celles qui étaient de la Sainte-Famille (à commencer par madame de Champigny et les femmes des membres du Conseil souverain), refusèrent, sauf trois qui furent expulsées sur-le-champ, à la grande colère du gouverneur $^{74}$.

Jusqu'à la fin du Régime français, la question des mondanités fut le talon d'Achille de cette confrérie. Durant l'hiver 1748-1749, la visite à Montréal de l'intendant Bigot suscita des festivités de toutes sortes. Tonnant du haut de la chaire contre ces plaisirs infâmes, les sulpiciens exclurent de la confrérie pour une période de trois mois toutes les dames qui étaient allées danser et demandèrent même à la supérieure, madame Feltz, de se retirer ${ }^{75}$. Personne n'était à l'abri de la sévérité du clergé. Madame Bégon elle-même, la belle-soeur de l'intendant, fut chassée

70 ASQ, Séminaire 6, no 73 r, 15 novembre 1689, Lettre de Glandelet à M. Boudon. (Ces dévotions commencèrent tout de suite après l'attaque des Iroquois contre Lachine). AHDQ, 361.

71 ANQ, greffe de Hiché, no 220, 10 septembre 1731. Testament de Marie Leroy veuve de Georges Regnard Duplessis.

72 Pierre-Georges Roy, Inventaire des ordonnances des intendants de la Nouvelle-France (Beauceville, l'Éclaireur, 1919), III: 242. André Vachon, «Jean Talon», DBC, I: 644.

73 Gustave Lanctôt, Histoire du Canada (Montréal, Beauchemin, 1967), II: 179.

74 Louis Bertrand de Latour, Oeuvres complètes (Migne, 1855), IV, col. 57.

75 Lettres au chef fils. Correspondance d'Élisabeth Bégon avec son gendre (1748-1753) (Montréal, Hurtubise HMH, 1972), 89. 
de la confrérie pour avoir pris part à un charivari ${ }^{76}$. Le clergé ne consentit jamais à relâcher ses exigences en ce domaine: il préférait exclure les indésirables plutôt que de renoncer au rôle édifiant qu'il voulait voir jouer par la confrérie.

\section{$b$ - La congrégation des filles externes}

Pendant que les ecclésiastiques de Québec et de Montréal s'évertuaient à détourner les dames de la Sainte-Famille des plaisirs mondains, les Soeurs de la Congrégation exhortaient les filles de la congrégation des externes à renoncer à toute vanité dans leurs vêtements. Elles obtinrent certains résultats. En juin 1686, la veille de la fête du SaintSacrement, les associées de Québec décidèrent de se défaire de certains rubans et colifichets qu'elles allèrent suspendre devant un autel de la Vierge comme pour les offrir en sacrifice. Le lendemain, elles assistèrent à la procession vêtues avec la plus grande simplicitée ${ }^{77}$. L'année suivante, les jeunes congréganistes de l'île d'Orléans imitèrent celles de Québec en décidant de se priver de «quelques ornements de tête» ${ }^{78}$. La religieuse qui rapporte ces faits édifiants ne précise pas toutefois combien de temps durèrent ces bonnes dispositions.

\section{c - La congrégation de la Vierge}

Les membres de la congrégation des messieurs de la ville de Québec se distinguaient par leurs activités pieuses et charitables. Au 17e siècle, ils se rendaient à l'Hôtel-Dieu, habituellement le jour d'une fête de la Vierge, pour payer et servir eux-mêmes un repas aux malades ${ }^{79}$. Monsieur de Tracy lui-même posa ce geste le jour où il fut reçu à la congrégation $^{80}$.

Parmi les gestes de piété, les congréganistes jouissaient du privilège de porter le dais du Saint-Sacrement à la procession de la FêteDieu $^{81}$ et ils organisaient un cortège funèbre spécial pour leurs défunts. Après la victoire de 1690 sur les Anglais, ils fondèrent cinq messes solennelles pour honorer le Très Saint-Sacrement de l'autel et rendre grâce pour cette faveur obtenue par l'intercession de la Vierge et de saint Joseph ${ }^{82}$. Le coût de la fondation, 1500 livres, nous donne une idée des ressources financières de l'association, même si les livres de

\footnotetext{
76 Ibidem, et notre article intitulé «La confrérie de la Sainte-Famille à Québec sous le Régime français», RSCHEC, 43 (1976): 79-93.

Étienne-Michel Faillon, Vie de la soeur Bourgeois, fondatrice de la Congrégation de Notre-Dame de Ville-Marie, suivie de l'histoire de cet Institut jusqu'à ce jour (Montréal, 1853), I: $322-323$.

78 Ibid., 324-326.

79 AMHDQ, Livres de comptes, années 1681, 1682, 1683, 1684.

$80 J J, 347,15$ août 1666 .

81 Souvenir du deux cent cinquantième anniversaire de la congrégation Notre-Dame de Québec (Québec, Laflamme et Proulx, 1907), 21.

${ }_{82}$ ANQ, greffe de Genaple, 16 mars 1695.
} 
comptes sont perdus. En 1699, quelques personnes dévotes (probablement les congréganistes eux-mêmes) payèrent pour assurer l'entretien à perpétuité de la lampe de l'autel de la congrégation ${ }^{83}$. Les domestiques du Séminaire qui étaient associés à la congrégation contribuèrent également à la fondation de messes pour les âmes du purgatoire ${ }^{84}$.

Le dimanche avant-midi, les congréganistes avaient l'habitude de se réunir dans leur chapelle particulière, chez les jésuites, pour l'office propre à leur association. Cette façon d'agir devait leur attirer des difficultés. En 1694, les sulpiciens chargés de la cure de Montréal se plaignirent à l'évêque du fait que les récollets et les jésuites tenaient les assemblées du tiers ordre et de la congrégation le dimanche matin. Ils craignaient que par les froids matins d'hiver, les membres des confréries n'eussent aucune envie de venir à la messe paroissiale après avoir assisté à un office d'une heure et demie dans une chapelle particulière ${ }^{85}$.

Sensible à ces raisons, Mgr de Saint-Vallier interdit aux confréries de tenir leurs assemblées le dimanche avant-midi. D'où les gémissements du père de la Chauchetière: «Notre congrégation ne se tient plus qui avait plus de 50 congréganistes. ${ }^{86}$ Cet incident constituait un épisode parmi beaucoup d'autres de la rivalité traditionnelle entre clergé régulier et séculier. Sollicité par les sulpiciens eux-mêmes de contrôler les activités des deux autres communautés, Mgr de Saint-Vallier se vit accuser de tourmenter les religieux ${ }^{87}$ alors que son but avoué était simplement de favoriser la fréquentation des églises paroissiales comme le recommandait le concile de Trente. Le curé de Ville-Marie l'avait parfaitement compris en présentant les activités des religieux comme une menace pour les paroisses de Montréal et des environs.

Mais les jésuites constituaient un ordre trop influent pour qu'on ne tint pas compte de leurs désirs, c'est pourquoi Mgr de Saint-Vallier consentit à assouplir sa réglementation. Il permit aux congréganistes de s'assembler le dimanche matin à condition que leur réunion se termine tôt et que leurs dirigeants les pressent d'être fidèles à leur paroisse ${ }^{88}$. Les assemblées reprirent donc comme avant, mais il semble que les congréganistes ne prisaient pas outre mesure les cérémonies religieuses interminables et qu'ils regimbaient quand leur office durait plus d'une heure et demie ${ }^{89}$.

83 ANQ, greffe de Chambalon, 6 août 1699. 268,276 .

84 ANQ, greffe de Genaple, 29 février 1692. ASQ, Livre de comptes, 1688-1700, 213, de MM. du Séminaire de Montréal».

86 Lettre du jésuite Chauchetière à son frère, 7 août 1694, $R J, 64: 120$.

87 Ibidem.

${ }^{88} \mathrm{Mgr}$ de Saint-Vallier, «Ordonnance pour le règlement du diocèse», 8 octobre 1700 , MEQ, I: 407.

${ }^{89}$ Lettres du P.F.-X. Duplessis de la Compagnie de Jésus (J.-Edmond Roy, Lévis, Mercier et Cie, 1892), xxx, 19 novembre 1716. 


\section{d - La confrérie de Sainte-Anne}

Les faits et gestes des membres de la confrérie de Sainte-Anne ont soulevé beaucoup moins de commentaires que ceux des dames de la Sainte-Famille et de la congrégation. Par exemple, personne n'a relevé s'ils observaient ou non le règlement qui leur interdisait de participer aux bals et mascarades ${ }^{90}$.

D'après les livres de comptes, seule une minorité de confrères s'acquittaient de leur cotisation annuelle, mais les marguilliers de la confrérie réussissaient quand même à pourvoir à l'entretien de la chapelle, au paiement d'un service pour chaque défunt, plus un service solennel pour l'ensemble des défunts de la confrérie, le 27 juillet de chaque année. Un office spécial était célébré à tous les deux mois et on soulignait la fête patronale, le 26 juillet, par une messe solennelle, une procession et l'admission des nouveaux confrères. Cette fête ne semble pas avoir occasionné de festivités profanes, comme un banquet. Les livres de comptes ne mentionnent aucune dépense pour une telle fin et le clergé ne formula aucune doléance à ce sujet sous le Régime français.

Pourtant, en France, au $17 \mathrm{e}$ et au $18 \mathrm{e}$ siècles, les curés se plaignaient souvent des banquets des confréries de métiers ${ }^{91}$. Et dans la colonie même, à Montréal, la célébration de la Saint-Éloi par les armuriers dégénérait parfois en beuveries et querelles ${ }^{92}$. Ces désordres ne semblent pas avoir touché la confrérie de Sainte-Anne. A moins que tous les confrères soient allés joyeusement festoyer à Sainte-Anne-duPetit-Cap le 26 juillet?

Les activités des autres confréries sont moins bien connues. Tout au plus savons-nous que l'office du Rosaire et celui du Scapulaire étaient régulièrement célébrés à Notre-Dame de Québec, que les dames de la Sainte-Famille défrayaient le coût de l'entretien de leur chapelle à SaintAugustin de Desmaures ${ }^{93}$ et que celles de L'Islet fondèrent 2 messes: l'une pour le repos de l'âme des défuntes de l'association, l'autre pour obtenir qu'aucune d'elles ne mourut en état de péché mortel ${ }^{94}$.

La perspective des fins dernières amenait d'ailleurs les gens à rechercher les secours spirituels de leur association: en rédigeant leur acte de dernière volonté, $16,8 \%$ des testateurs firent un legs en faveur d'une confrérie, soit pour acquitter les cotisations en retard, contribuer

90 APNDQ, Ms 33, Cahier de la confrérie de Sainte-Anne, s. d., 7. «Règles et Statuts de la confrérie, 1678».

91 Gérard Cholvy, dir., Histoire du diocèse de Montpellier (Paris, Beauchesne, 1976), 154. Jean Matet et Robert Pannet, «Vialart, évêque de Châlons», dans Bernard Plongeron et Robert Pannet, Le christianisme populaire. Les dossiers de l'histoire (Le Centurion, 1976), 151.

92 Édouard-Zotique Massicotte, «La Saint-Éloi et la corporation des armuriers à Montréal au XVIIe siècle», Bulletin des recherches historiques, 23 (1917): 343-346.

93 AP, Saint-Augustin, Dossier sans titre, 75.

94 AP, L'Islet, registre de la confrérie de la Sainte-Famille, 1842-1911. «Extrait du registre relié en parchemin et marqué par la lettre A. Règlement fait par les dames de la Sainte-Famille en $1749 »$. 
au paiement du service funéraire prévu par les règlements ou contribuer à la décoration de la chapelle ${ }^{95}$. En échange, ces donateurs demandaient, parfois avec insistance, que l'on n'oublie pas de prier à leur intention.

\section{CONCLUSION: UN BILAN POSITIF}

Le clergé de la Nouvelle-France visait donc le même but que celui de la mère patrie en organisant des confréries: tous deux souhaitaient promouvoir la sanctification des fidèles en les incitant à fréquenter régulièrement les sacrements et à mener une vie irréprochable. La dévotion envers le saint patron devait se manifester d'abord et avant tout par l'imitation de ses vertus, et ensuite par l'entretien d'une chapelle et la participation aux cérémonies qui lui étaient dédiées. Des indulgences octroyées libéralement récompensaient ces activités, mais la conversion sincère demeurait la condition de base pour les obtenir.

D'autres préoccupations du clergé post-tridentin apparaissent dans le contrôle exercé par les évêques sur les activités des confréries canadiennes. Par exemple, la volonté de renforcer l'organisation paroissiale (les ordres réguliers devant seconder le clergé de la paroisse et surtout ne jamais lui nuire) et une attitude très austère, voire carrément hostile, face aux divertissements mondains: bal et mascarade.

Sur deux autres points cependant, la ligne de conduite suivie par les évêques du Canada différait sensiblement de celle de leurs confrères français. D'abord, nous n'avons pas retrouvé dans le gouvernement de Québec de confrérie du Saint-Sacrement, qui était la plus favorisée par les évêques de France (cette dévotion toutefois était pratiquée dans d'autres confréries), ni de confrérie de charité (mais les dames de la Sainte-Famille se chargeaient de secourir les pauvres). Mais le trait le plus remarquable de l'institution des confréries en Nouvelle-France demeure la place prépondérante que le clergé octroya à la confrérie de la Sainte-Famille, la responsabilité qu'il confia aux femmes de répandre la dévotion dans leur famille. Toutefois, ce domaine d'influence attribué aux femmes ne doit pas nous faire illusion sur le degré d'autorité qu'on leur concédait, que ce soit dans le milieu familial (on prêchait aux dames de la Sainte-Famille la soumission à leur mari) ou au sein d'une confrérie (la supériorité numérique des femmes dans la confrérie de Sainte-Anne ne leur permit jamais d'accéder aux postes de direction).

Il est difficile de savoir jusqu'à quel point les confréries ont pu contribuer à répandre dans la colonie l'habitude de la confession et de la communion mensuelles et de la recherche d'indulgences. Par contre,

95 Marie-Aimée Cliche, «Les attitudes devant la mort d'après les clauses testamentaires dans le gouvernement de Québec sour le Régime français», Revue d'histoire de l'Amérique française, 32,1 (juin 1978): 57-94. 
nous savons que ces associations ont participé à l'embellissement des édifices du culte (en entretenant leur chapelle), et à la dévotion envers les morts (en faisant dire des messes pour les confrères défunts et en escortant leur convoi funéraire). Si on ajoute à cela le fait que les confréries de Québec ont su se garder des déviations profanes que l'on déplorait en France, on peut conclure que ces associations ont bien rempli leur rôle qui était d'animer la dévotion populaire, même si elles n'ont pas réussi à amener tous leurs membres à ce haut niveau de perfection chrétienne souhaité par le clergé post-tridentin. 